\title{
Translation Manipulated by Ideology and Poetics-A Case Study of The Jade Mountain*
}

\author{
Mei Zhang \\ School of Literature and Law, Sichuan Agricultural University, China \\ Email: gtmabele@163.com
}

\begin{abstract}
Beyond the traditional linguistic analysis in translation studies, this paper goes further to look into the relationship between translation and history, society, and culture. According to André Lefevere, translation is a rewriting or manipulation of an original text and all rewritings reflect a certain ideology and poetics. This paper takes Witter Bynner's translation The Jade Mountain as an example to elaborate how ideology and poetics manipulate poetry translation, including the choice of theme and translation strategy. Generally speaking, if translations are not in conflict with culture's ideology and dominant poetics, they are easier to be accepted. That's the reason why The Jade Mountain has received great popularity both as translations from the Chinese and as English poetry in the West.
\end{abstract}

Index Terms - manipulation, ideology, poetics, translation, The Jade Mountain

\section{THEORETICAL REVIEW}

Translation studies have set foot in many different areas up to now. As the linguistic-oriented studies of translation have declined, the cultural-oriented descriptive approach has been prominent over the past decades. The descriptive approach has its origin in comparative literature and Russian Formalism. The idea of literary polysystem shows that different literatures and genres, including translated and non-translated works, compete for dominance. André Lefevere (1946-1996) moved away from polysystem terminology to examine translation as "rewriting" and consider the role of ideology, poetics and patronage in the system of translated literature. Lefevere dismisses the kinds of linguistic theories of translation, which "have moved from word to text as a unit, but not beyond" (Lefevere, 2005, p.87) without considering the text in its cultural environment. Instead he goes beyond the limitation of language and focuses on the interaction between translation and culture. The kennel of Lefevere's translation theory is the theory of manipulation or rewriting. According to him, any work is not translated in vacuum, which is certainly manipulated or rewritten in a certain form for a certain reason. Ideology and dominant poetics are two main reasons influencing the translation. In addition, he introduced the concept of patronage, which also plays an important part in the translation. According to him, there are two control factors in literary system. The first, within the literary system, is represented by the "professional", including critics, reviewers, teachers and translators. The second, outside of the literary system, is called "patronage". Patronage is usually more interested in the ideology of literature than in its poetics, while professionals are more concerned with poetics.

By "ideology", Lefevere understands, "a set of discourses which wrestle over interests which are in some way relevant to the maintenance or interrogation of power structures central to a whole form of social and historical life" (Shuttleworth, 2004, p.136). If translations are not in conflict with culture's ideology (standards for acceptable behavior in the target culture) (Shuttleworth, 2004, p.87), they are easier to be published. While if the source text collides with the ideology of the target culture, translators may have to modify or leave out the offending parts. Ideology is the most important consideration, which refers to the translator's ideology which he/she willingly accepts or the ideology imposed upon the translators by patronages. Different ideology may produce different translations, because most translators would state their culture's ideology to make their translations published easily. Translators are always caught in the paradox between his ideology and his status as a professional. They can't produce a text opposite to their ideology, at the same time they must convince other professionals that they are worthy of being a translator. Nobody can escape one's own ideology, which suggests that claiming objectivity is "dishonest" (Gentzler, 2004, p.138). "Faithful translation is often inspired by a conservative ideology" (Lefevere, 2005, p.51), but it is utopia to be thought as the only translational strategy possible or allowable, because translation always takes place within a certain ideology and poetics.

Dominant poetics is taken into consideration by Lefevere to examine the concrete factors that systemically govern the reception, acceptance or rejection of literary texts. He analyzes dominant poetics into two components: literary devices and the concept of the role of literature. The former includes the range of genres, symbols, leitmotifs and prototypical situations and characters and the latter is the relation of literature to the social system in which it exists (Munday, 2001, p.129). The first component exerts more conservative influence on the literary system; while the second component tends to exert more innovative influence, which is closely tied to ideology in the social system and

\footnotetext{
*A Project Supported by Scientific Reserch Fund of SiChuan Provincial Education Department.
} 
influences the selection of the theme relevant to the social system if the work is to be noticed. He sees the dominant poetics as tending to be determined by ideology. Translations, deeply "affect the interpenetration of literary systems" (Lefevere, 2005, p.38) not only by creating the image of one writer or work in another literature, but also by introducing new things into the first component and paving the way to changes in its second component. Translations play an important part in the evolution of the literary system, because "the struggle between rival poetics is often initiated by writers, but fought and won or lost by rewriters" (Lefevere, 2005, p.38). Translation is "as important as original writings in the establishment of the poetics of a literary system". (Lefevere, 2005, p.28)

\section{INTRODUCTION TO THE JADE MoUntAIN}

The Jade Mountain is an English version of Three Hundred Poems of the T'ang Dynasty translated by Witter Bynner (1881-1968), an American writer, poet and scholar, in collaboration with the Chinese scholar Kiang Kang-hu (1883 - 1954). The source anthology was compiled in 1763 by Sun Zhu (1711 - 1778) in Qing Dynasty, by far the most popular and classical anthology of Tang poems in China due to its refined selection, rational organization, and complete poetical forms. The original anthology contained 310 poems by 77 Tang poets, arranged by subdivisions of the form, including ancient verses of five or seven characters, regular verses of five or seven characters, quatrains of five or seven characters and folk songs. This anthology are planned to be a textbook for children and to be useful until one's hair is white. The common saying is almost known to every household in China - Learning three hundred Tang poems by heart, you can chant poems though you know not the art. This anthology has remained the most popular anthology of Tang poetry and may possibly be the best way to gain a preliminary conception of ancient Chinese literature. Bynner regarded it as "a collection of far wider popularity in China than, say, The Golden Treasury in America". (Bynner, 1978, p.6)

Bynner and Kiang chose this anthology right due to its lasting popularity and great influence on Chinese literature and culture, instead of basing their choice of the source text on their interest which is traditionally the main inspiration for most western translators as to translating Chinese poems. The name of The Jade Mountain derives from "Is either the tip of earth's Jade Mountain, or a moon-edged roof of paradise" (Bynner, 1978, p.108) translated from the lines written by Li Bai, the most famous poet in Tang Dynasty. Before the anthology of translations was first published in 1929 by Alfred A. Knopf, Inc., many of them had been published piecemeal in various magazines and newspapers, either dominant or not at that time, such as Little Review, Asian, The China Review, The Literary Review, Bookman and Literary Digest. The anthology was rearranged, according to the alphabetical order of the poets' surnames rather than the poetic forms in the original, "since the prosodic differences that distinguish the various categories of the original are largely obscured in translation" (Watson, 1978, p.17). The Jade Mountain has been widely accepted in the western world and has been reprinted again and again and now even becomes the authorized English version of Three Hundred Poems of the T'ang Dynasty in electronic library. According to Biography of Witter Bynner in Gale Databases, The Jade Mountain was the first complete volume of Chinese poetry to be translated by an American. As Divid Lattimore says, "The Jade Mountain was and is the only complete rendering, in any Western language, of a standard Chinese anthology, combing readability and poetic feeling with better than average accuracy and enjoyed enduring favor in college courses devoted to world literature or to East Asian civilization. But its appeal is not limited to the classroom. Tributes to it by Arthur Waley and Kenneth Roxroth have probably helped to maintain its position as an influence on modern Anglo-American poetry" (Lattimore, 1978, p.309). As Burton Watson says, this book "stood up over the years both as translations from the Chinese and as English poetry". (Watson, 1978, p.15)

\section{MANiPulation of The JADE Mountain By IDEOLOGY}

Before the early $20^{\text {th }}$ century, most eastern countries were still considered inferior to the western world. It's no wonder that eastern literature was always ignored and treated as "low" literature, since ideology is one of the main factors influencing literary system. However, the first decades in the $20^{\text {th }}$ century, when The Jade Mountain was translated, is the prosperous period for the Chinese poems translated and accepted in America for some ideological reasons.

First, during the first two decades, the world experienced great changes in political and economic structure, which led to changes in other aspects of life including changes in literary system. The most important event was the First World War (1914-1918), which had a profound impact on the whole society. Shortly after the war there appeared an economic boom, but the unexpected economic crisis befalling America in 1929 fragmented many people's dream, so that "excitement and enthusiasm subsided to make way for disillusionment"(Chang Yaoxin, 1990, p.217). Western faith is closely connected with Christianity. After the First World War, all forces seemed to be pulling apart. It seemed that "there was no mythical center with god expelled from the universe... with nothing to mediate between man and his cosmos" (Chang Yaoxin, 1990, p.217). When the loss of faith was intensified, a new remedy must be found to eliminate people's chaotic and fragmented sense of life and keep the stability of the whole society. As Bynner said, "Tang poets, living their Taoism, had eased meship into the whole current of life itself, no god or man intervening". (Bynner, 1978, p.4) Against the burdens of life, the Tang poets could find "an inner peace and a good will toward men" and in the Tang poems permeates the sense of "oneness in man, nature and eternity" (Bynner, 1978, p.4). As mentioned before, the 
selection of the theme is relevant to the social system. All of the spirits reflected in Tang poems could help to revive westerners' confidence in simplifying, cleansing and strengthening their lives, which may be considered as a prerequisite for Tang poems including The Jade Mountain to be translated and well accepted in America.

Second, After the First World War, America broke through its isolation geographically and proved its economic and political power in the world. American intellectuals were eager to broaden their vision and took great curiosity in learning the society outside, especially the mysterious eastern civilization. An understanding of people in the Orient has arisen and oriental thought and art has reached the West. Chinese civilization, "to be not only the oldest civilization still vigorous but to be a civilization profoundly informed as to lasting values"(Bynner, 1978, p.11) aroused great interest in western world. Ezra Pound's Cathay (1915) and Amy Lowell's Fir-Flower Tablets (1921) triggered the upsurge of the English translation of Chinese poems in America. Though Pound's translation received great popularity in America, but Cathay only contained nineteen poems, from which English readers couldn't appreciate the complete picture of Chinese poems. Lowell's translation was criticized by Bynner "for the exaggerated use of root-meaning in Chinese characters, so that under their hands what was natural, direct, every-day expression in the orient would become in English odd or complex or literary" (Bynner, 1978, p.7). In comparison with the two anthologies mentioned above, the brevity of Three Hundred Poems of the T'ang Dynasty is an appropriate choice as an introduction to English readers in Bynner's times, "when they had little or no knowledge of Chinese poetry" (Watson, 1978, p.17). More importantly the source anthology Three Hundred Poems of the T'ang Dynasty is a classic anthology which had gained great popularity in China. This anthology contains the essence of Chinese literature and culture, undoubtedly worthwhile introducing to the western readers. Bynner and Kiang made their decision to translate it into English, right fit for the temper of the age.

Meanwhile translator's ideology is well reflected in Bynner's choice of translation strategy. For example, in translating names of person and place, Bynner thinks for readers in English it is better to eliminate or use only seldom the names of place and persons not highly important to the sense of a poem. However, in a country as old as china, place names naturally come to have rich historical or legendary associations and "their mere mention in literature is sufficient to call up scenes of departed glory, fierce battles, the excitement of a bustling city, or the loneliness of the frontier" (Watson, 1971, p128). When translating such names, Bynner tried to make a careful adjustment in order to completely reproduce the original as well as to make it easier understood by western readers. He substitutes more general geographical terms for specific place names in the original, for example, in Du Fu's poem "Both Sides of the Yellow River Recaptured by the Imperial Army", Bynner translates the lines as "Back from this mountain, past another mountain, / Up from the south, north again----to my own town!". Bynner uses the general geographical terms "this mountain", "another mountain", "south", "north" instead of four specific place names in the original: "Ba Xia", "Wu Xia", "Xiang Yang, "Luo Yang". It is reasonable for Bynner to translate in this way since western readers are unfamiliar with these places, but to the disadvantage the translation only locates the place so roughly that target readers can't feel the sharp shift from water route to land route as Chinese readers can. In addition, Bynner replaces some current names for their ancient use. For example, "Jin Ling" is translated into "Nan-King", "Guang Ling" into "Yang-chou", "E Zhou" into "Wu-ch'ang" and "Tu Bo" into "Tibetan". According to Bynner, it will do well to the scholars' studies on Chinese ancient geography; meanwhile make it more acceptable among the American readers in his times. In regards to translate names of persons, Bynner makes occasional unimportant omissions. Bynner has omitted the "ninth-born" or "nineteenth-born", frequently added in the original to names of persons, meaning the ninth or nineteenth child in a family. In translating the names unfamiliar in the Occident, Bynner often employs the name and qualities of some other familiar ones. Taking the translation of instruments as an example, he translates "Hu Jia "(a kind of ancient instrument used by ancient people in the northern border of China) into "Flageolet", and translates "Bi Li"(another kind of ancient instrument in China) into "Reed-pipe". Some other translators translate the two kinds of instrument both into "Tartar Pipe". Clearly "Flageolet" is a kind of western instrument, which completely changes the atmosphere of the original poem. "Reed-pipe" shows the quality of the instrument, while it misses its culture-loaded meaning. In the article "Poetry and Culture" Bynner commented, "Whenever possible, I have avoided phraseology which, natural and familiar in Chinese, would be exotic or quaint in English; I have hoped rather to accent in these Tang masterpieces the human and universal qualities by which they have endured"(Bynner, 1978, p.44), which clearly reflects the translator's ideological manipulation of the translation.

\section{Manipulation of The Jade Mountain by Poetics}

At the end of the $19^{\text {th }}$ century, most American poets still imitated their past masters. Traditional English poetics was characterized with "its iambic pentameter, its verbosity, and extra-poetic padding" (Chang Yaoxin, 1990, p.219). Especially during the Victorian period, the dominant poetics of poetry writing was the strict regular form, such as iambic pentameter. Dominant poetics is closely tied to ideology in the social system. The new age demanded proper literary form to express the temper of the age, so the conventional dominant poetics was confronted with the challenges of a new verse form to suit the great social changes. In America Walt Whitman published his Leaves of Grass by using free verse, which challenged the conventional dominant poetics to a great degree. After the First World War, more and more modern poets began to use free verse so as to develop a rich rhythm and splendid thoughts, such as the poets W. H. Auden and T. S. Eliot.

Free verse is indeed a term describing various styles of poetry without using strict meter or rhyme, but that are still 
recognizable as "poetry" with a certain form. Free verse "went as far back as Milton, but it was with the imagists that it became a legitimate poetic form" (Chang Yaoxin, 1990, p.221). An early usage of the term appears in 1915 in the preface to an Imagist anthology, which states, "We do not insist upon 'free-verse' as the only method of writing poetry. We fight for it as for a principle of liberty" (Chang Yaoxin, 1990, p.221). In the first years of $20^{\text {th }}$ century, a group of English and American poets came together to write poetry in a new way, to express themselves through a series of clear, exact images. They were greatly inspired by the Chinese classic poetry, as Marcus Cunliffe said, "In Chinese and Japanese verse, they found the perfect reticence: word distilled" (Cunliffe, 1986, p.248). Ezra Pound, the leader of Imagism, who borrowed heavily from Chinese ideograms and Japanese haiku to change a system overburdened with metrical forms by breaking through obsolete themes, abstract preach, verbose expression and constrained form. Obviously since the modern English poetry movement the dominant poetics of English poetry writing tended to shift from regular form to free verse.

In a literary system, the dominant poetics in the native literature may influence the poetics of translation greatly. In the early $20^{\text {th }}$ century, modernism dominates the world of arts and literature. Traditional metrical poetic form was questioned and rejected by modern poets, which varied the trend of poetry translation correspondingly. Even those influential translators, such as James Legge, Herbert A. Giles and W. J. B. Fletcher were challenged on their metrical translation strategy (Zhu Hui, 2008, p.81). On the contrary, free verse translation boomed during this period, such as Ezra Pound's Cathay (1915), Arthur Waley's 170 Chinese poems (1918), Amy Lowell and Florence Ayscough's Fir-Flower Tablets (1921). Ezra Pound's Cathay received great popularity in the west. As Xu Yuan-zhong said, "Almost all the earlier translators tried to translate classical Chinese verse into English rhyme. Ezra Pound (1885-1972) was the first to render Chinese poetry into free verse in his Cathay". (Xu Yuan-zhong, 1991, p.35) Another remarkable free verse translation was attributed to Arthur Waley (1889-1966), who develops an extremely successful type of free verse based on "sprung rhythm" that avoids redundancy of fixed-meter rhyming English prosody in order not to sacrifice sense to sound. As for Amy Lowell, she considered it more important to reproduce what she called "the perfume of a poem than its metrical form" (Bynner, 1978, p.38).

When Bynner began making translations from Chinese poetry around 1920, translation of Chinese poetry in English free verse had been popular in the western world. Bynner's translation was right fit for the dominant poetics of his times, that is, to follow the mainstream of free verse translation. Therefore it's no wonder that Bynner's translation received great popularity in his times. It is safe to say one of the principal reasons why Bynner's translations remain readable and exciting even today is that he translates these poems in the form of free verse by reproducing the meaning of the original poems beyond the limitation of the metrical form. On the other hand, Bynner's free verse translation was still faced with great challenges. In his times, free verse translation had not yet completely accepted, as Burton Watson said, "Free verse itself was still highly controversial, and its application to Chinese translation was deplored by many, as it continues to be in some quarters today"(Watson, 1978, p.25). Furthermore, "Free verse, despite its deceptive title, is an extremely difficult form to handle, particularly when applied to translation"(Watson, 1978, p.26), so it is a forbidden task for Bynner to translate an entire Chinese anthology into free verse, rather than to select merely those poems that he felt would come across well in English.

\section{CONCLusion}

According to André Lefevere's Rewriting or Manipulating Theory, translation is manipulated by some extrinsic factors such as ideology, dominant poetics and patronage, among which ideology is the deciding one. Generally speaking, when the translation conforms to the ideology or dominant poetics in the receiving culture, it is easier to be accepted. While if it collides with the ideology of the target culture, translators may have to modify some parts to fit for it if he wants his translation to be published easily. Bynner's translation The Jade Mountain has received the great popularity in America since it was produced around 1920s, exactly because it serves as a new remedy to eliminate people's chaotic and fragmented sense of life after the First World War and caters to the western people's great curiosity in learning mysterious eastern civilization. Of course the translator's ideology also includes the one he/she willingly accepts except for the one imposed upon the translators by patronages. Translator's ideology is well reflected in Bynner's choice of translation strategy. For example, in translating names of person and place and the names unfamiliar in the Occident, Bynner removes some parts not highly important to the sense of a poem or replace the expressions which are natural and familiar in Chinese, but exotic or quaint in English. Obviously no one can escape his own ideology, so that the absolute "faithful translation" is utopia to be thought as the only translational strategy possible or allowable, because translation always takes place within a certain ideology and poetics. As we have said before, dominant poetics is the other main factor manipulating translators' translation strategy; meanwhile translation in return may enhance or overthrow the current dominant poetics because "the struggle between rival poetics is often initiated by writers, but fought and won or lost by rewriters" (Lefevere, 2005, p.38). Obviously Bynner's translation rejected the traditional poetics and followed the new trend of poetry writing and translation in the form of free verse, which also made a great contribution to the evolution of free verse in English world.

\section{REFERENCES}


[1] Bynner, Witter. (1978). The Jade Mountain. In Kraft, James (ed.) The Works of Witter Bynner. New York: Farra, Straus, Gioux.

[2] Cunliffe, Marcus. (1986). The literature of the United States. New York: Penguine Books.

[3] Gentzler, Edwin (2004). Contemporary Translation Theories. Shanghai: Shanghai Foreign Language Education Press.

[4] Hui, Zhu. (2008). Studies on English Translation of Chinese Poetry in England and the United States. Shanghai: Shanghai Foreign Language Education Press.

[5] Lattimore, Divid. (1978). An introduction to The Way of Life According to Laotzu, In Kraft, James (ed.) The Works of Witter Bynner. New York: Farra, Straus, Gioux.

[6] Lefevere, André. (2005). Translation, Rewriting and the Manipulation of Literature Fame. Shanghai: Shanghai Foreign Language Education Press.

[7] Munday, Jeremy. (2001). Introducing Translation Studies. London and New York: Routledge.

[8] Shuttleworth, Mark \& Cowie, Moira. (2004). Dictionary of Translation Studies. Shanghai: Shanghai Foreign Language Education Press.

[9] Watson, Burton. (1971). Chinese Lyricism. New York: Columbia University Press.

[10] Watson, Burton. (1978). Introduction to The Jade Mountain. In Kraft, James (ed.) The Works of Witter Bynner. New York: Farra, Straus, Gioux.

[11] Yaoxin, Chang. (1990). A Survey of American Literature. Tian Jin: Nan Kai University Press.

[12] Yuan-zhong, Xu. (1991). Development of Verse Translation. Journal of Foreign Languages, 1, 33-40.

Mei Zhang is currently a teacher of English and Chinese-English translation in Sichuan Agricultural University, China. She received MA degree in translation from Sichuan University and BA degree in English Education from Sichuan Normal University, China. Her research interests include language teaching and Chinese-English translation. She has published about ten papers in academic journals. 